\title{
Aspects regarding the specific tests applicable to electric motors with type of protection increased safety ,e”
}

\author{
Dragoş Fotău ${ }^{1 *}$, Mihai Magyari ${ }^{1}$, Lucian Moldovan ${ }^{1}$ and Diana Sălăşan ${ }^{1}$ \\ ${ }^{1}$ National Institute for Research and Development in Mine Safety and Protection to Explosion - \\ INSEMEX Petroşani, 32-34 G-ral Vasile Milea Street, Petroşani 332047, Romania
}

\begin{abstract}
Evaluation of explosion-proof protected electrical equipment in scope of certification is extremely important considering the risk of explosion that has to be minimized in order to ensure life safety and health of workers and to prevent damaging of property and the environment, as well as free movement of goods when they meet the essential safety requirements at European level.

Most of the equipment operating in potentially explosive atmospheres is represented by electric motors, which in most situations act on various other elements (e.g. pumps, valves, fans etc.).

Even if electric motors for explosive atmospheres are designed and manufactured following some of the same principles as the ones used for other electric machinery, they have certain particularities related to their field of use.

Thus, a series of specific restrictions and tests are required to be considered in their case. The purpose of this paper is to present the importance of the specific tests for electric motors with type of protection increased safety „e" designed to be used in explosive atmosphere.
\end{abstract}

\section{Introduction}

The purpose of this paper is to identify the improvements to be made on test stands for electric motors that are used in potentially explosive atmosphere.

Using electric equipment in potentially explosive atmospheres brings forward several particularities therefore the problems that appear during the design, construction and operation of electrical devices and installations brings forward numerous difficulties, their approach requiring special attention considering all the technical, economical and labor safety aspects. Due to this fact, it is very important that the equipment is properly tested during the certification process.

This paper presents a series of tests applied to electric motors and type of protection increased safety, namely: the voltage impulse ignition test and the overvoltage-ignition test, and the test for determination of the maximum surface temperature.

Evaluation of explosion-proof protected electrical equipment in scope of certification is extremely important considering the risk of explosion that has to be minimized in order to

\footnotetext{
* Corresponding author: dragos.fotau@insemex.ro
} 
ensure life safety and health of workers and to prevent damaging of property and the environment, as well as free movement of goods when they meet the essential safety requirements at European level [1].

The evaluation of explosion-protected electrical equipment with type of protection increased safety is carried out by means of tests and verifications performed on the basis of the reference standards (SR EN 60079-0 - which includes the general requirements for all explosion-protected electrical equipment and the standards specific to the types of protection involved in the manufacture of the equipment ). In the case of increased safety protection type, the specific standard is SR EN 60079-7 [2, 3].

The type of protection means the specific measures applied to electrical equipment to avoid ignition of a surrounding explosive atmosphere.

\section{Tests carried out on electric motors with type of protection increased safety}

In order to verify explosion protection, the representative samples made available by explosion-protected equipment manufacturers are tested under the most unfavourable conditions that may occur in operation.

Most of the equipment used in technical installations in potentially explosive atmospheres (refineries, fuel depots, gas stations, dyestuffs, etc.) are electric motors, which in most situations act on various other elements.

\subsection{Electrical tests carried out on electric motors with type of protection increased safety}

The "e" increased safety type of protection implies equipment that does not produce electric arcs, sparks or excessive temperatures on any of the interior or exterior parts of the equipment, because of that it is necessary that these phenomena to be avoided.[3]

Because electric motors with increased safety type of protection (eb), whose supply voltage exceeds $1000 \mathrm{~V}$, pose a high risk of sparks occurring in windings (due to the choice of an inadequate method of winding insulation), it is necessary to perform tests to verify that winding insulation is adequate and does not lead to electric discharge (by electric arcs or sparks) at winding levels [3].

This sparking risk in the winding occurs at weak insulation spots when the charge in the weak spot becomes too high. This weak spot is excessively stressed during the operation of the electric motor or during the high-voltage test. This weak spot cannot resist this increased stress. As a result there is a partial breakdown in this location. This partial breakdown is referred to as partial discharge. However, the remaining insulation can still resist the increased voltage stress so that there is not a complete breakdown $[4,5]$.

The tests by which these aspects are tested are the impulse ignition test and the overvoltage-ignition test, applicable to electric motors with type of protection increased safety.

Insulation systems and connecting cables shall be tested in an explosive test mixture as presented in Table 1. They shall be subjected to 10 voltage impulses of not less than three times peak phase to earth voltage and with a voltage rise time between $0,2 \mu$ s and $0,5 \mu \mathrm{s}$ and with a time to half value which is at least. No ignition of the explosive test mixture shall occur $[7,8]$.

Insulation systems and connection cables shall be tested in an explosive test mixture, with a sinusoidal voltage of at least 1.5 times the rated r.m.s. line voltage for at least 3 min. The maximum rate of voltage rise shall be $0.5 \mathrm{kV} / \mathrm{s}$. The voltage shall be applied between 
one phase and earth with the other phases earthed. No ignition of the explosive test mixture shall occur [3].

Table 1. Explosion test mixtures.

\begin{tabular}{|c|c|}
\hline Equipment group & $\begin{array}{c}\text { Test mixture in air } \\
\mathrm{v} / \mathrm{v}\end{array}$ \\
\hline II C & $(21 \pm 5) \%$ hydrogen \\
\hline II B & $(7.8 \pm 1) \%$ ethylene \\
\hline II A & $(5.25 \pm 0.5) \%$ propane \\
\hline
\end{tabular}

Within the National Institute for Research and Development in Mine Safety and Protection to Explosion - laboratories were performed impulse ignition test for stator insulation systems on electric motors used in potentially explosive atmosphere [9-11], as exemplified in Figure 1. To carry out these tests were used specific testing equipment like: Oxygen analyser SERVOMEX 2200, Baker surge tester D12R, PP24 -impulse generator. The tests were carried out with an explosive mixture whose characteristics correspond to the requirements (concentration $-22 \%$ hydrogen, test temperature $-22^{\circ} \mathrm{C}$ ).

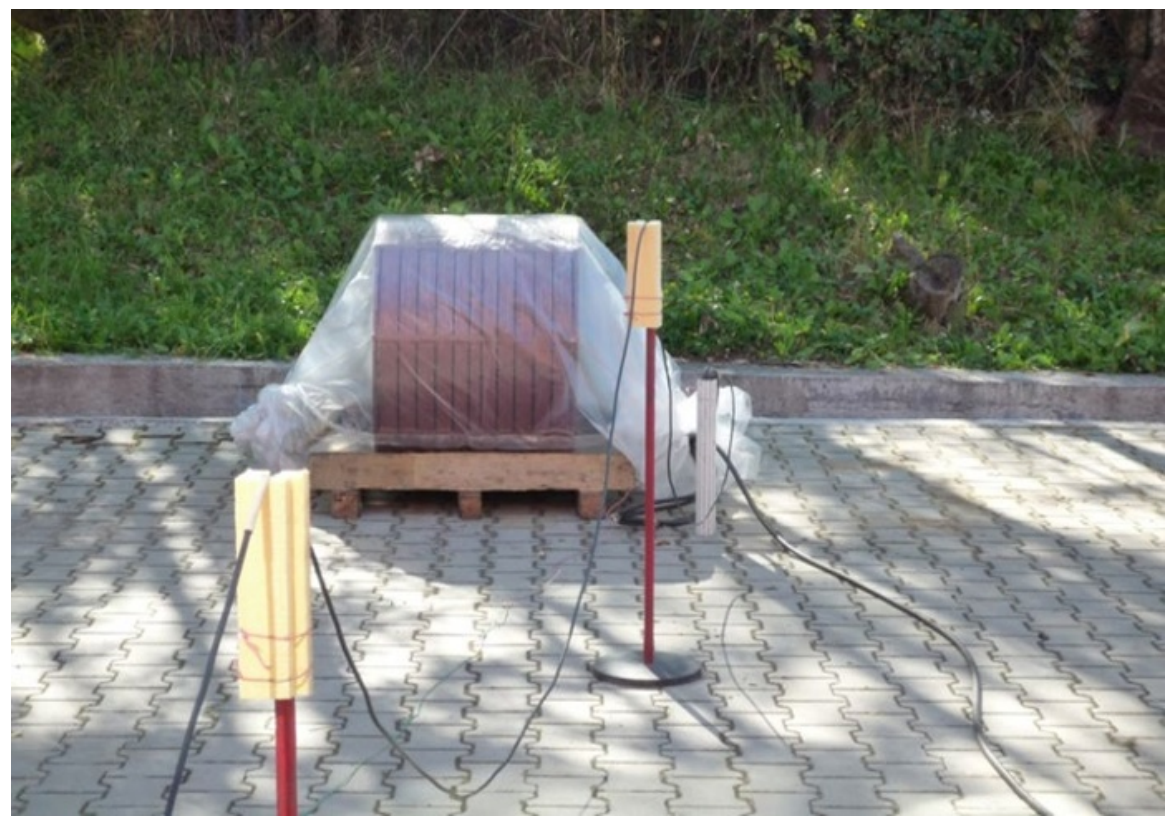

Fig. 1. Electric motor Ex e II C T2; $1300 \mathrm{~kW} ; 3000 \mathrm{rpm} ; 11 \mathrm{kV}$ subjected to impulse ignition test for stator insulation systems.

Pre-start purge may be adopted for Ex eb and / or Ex ec motors at risk of incendive sparking, and is designed to purge clean air through the motor enclosure to remove any residual potentially flammable gas. Its purpose is to prevent the risk of explosions due to rotor sparking during starting; air flow sensors and pre-start timers may monitor this purge process before allowing the application of the HV electrical supply, or control may be achieved by procedures. Once the motor is started, no further pre-purge flow is provided. A 
suitable purge connection point should be provided by the manufacturer. The purge gas supply is provided by the user, from a fixed supply or from portable gas bottles. (Nitrogen is sometimes used instead of using clean air) [6].

Ignition risks owing to stator sparking may also occur when the motor is running; this phenomenon has only been acknowledged relatively recently. Note that pre-start purge does not offer any protection, but suitable special measure might be to pressurise the motor enclosure continuously in order to prevent the ingress of a potentially flammable atmosphere; this arrangement should be interlocked with pre-start and post shut-down timers and pressure/flow measurement, but may not fully comply with the standard for Ex $\mathrm{p}$ apparatus $[9,10]$.

\subsection{Thermal tests carried out on electric motors with type of protection increased safety}

A very important component on which the explosion protection depends is the surface temperature of the equipment. This is the highest temperature reached in operation under the most unfavorable conditions (but within the tolerances set), $y$ any part or surface of the electrical equipment (in the case of gaseous explosive atmospheres, this temperature may appear on an internal component or on the outer surface of the case, depending on the type of protection used).[2]

For electrical equipment that can normally be used in different positions, the temperature must be determined for each position.

Measuring devices (thermometers, thermocouples) and connecting cables must be chosen and arranged so as not to significantly affect the thermal behavior of the electrical equipment. The final temperature is considered to be reached when the temperature rise gradient does not exceed $2 \mathrm{~K} / \mathrm{h}$ [3].

In addition to determining the maximum surface temperature of the equipment, it is necessary to determine the service temperature. Testing for service temperature and maximum surface temperature are part of the technical tests to which electrical equipment intended to be used in potentially explosive atmospheres is subjected.

For electrical machines, the maximum surface temperature may alternatively be determined at the most unfavourable test voltage in "Zone A" according to CEI 60034-1. In this case, the equipment must be marked with the symbol " $\mathrm{X}$ " and the specific conditions of use must include the information that the surface temperature determination was based on "Zone A" (CEI 60034-1) operation, generally $\pm 5 \%$ of the nominal voltage. For electric machines driven by a converter, the variation of the test voltage for determining the maximum surface temperature must be applied to the motor-converter system, taken as a whole, that is applied to the input of the converter and not to the input of the motor.[4]

Small asynchronous machines with a rated output of less than $5 \mathrm{~kW}$ generally display the maximum surface temperature when operating at a voltage that is higher than the rated voltage, due to core losses and magnetization current, which increases rapidly as the magnetic core becomes saturated at higher applied voltage.

Asynchronous machines with a rated power between $5 \mathrm{~kW}$ and $20 \mathrm{~kW}$ are influenced by several factors that determine performance and it is not possible to predict the priority effect without having detailed knowledge of the specific concept [4].

Asynchronous machines with powers greater than $20 \mathrm{~kW}$ generally exhibit the maximum surface temperature when operating at a voltage that is less than the rated voltage due to the higher I2R losses due to higher currents. In this case, these losses are generally higher than those that would result from core losses and magnetization current resulting from an applied voltage that is greater than the nominal voltage $[9,11]$. 
For rotating electric machines powered by a frequency converter, the increase of the maximum surface temperature should be determined under the most unfavorable conditions using one of the test methods below [5]:

- Specific converter (the machine should be tested with the intended converter).

- Comparable converter (the machine can be tested using a comparable converter when there is sufficient information to evaluate the comparison). Additional security factors can be applied to take account of the degree of comparability.

- Sinusoidal power supply (in this case the torque of the machine should be proportional to the square of the engine speed, the engine should be loaded with maximum load at rated speed. Additional security factors can be applied to take account of the degree of comparability).

The rotor can become significantly warmer than the stator. The significance of the problem varies depending on the type of protection. Determination of rotor temperature is very important for motors using protection type "e", but it can also be important for motors using protection type "d" when the hot rotor leads to the transfer of those high temperatures to the bearings and to the outside of the shaft.

\section{Conclusions}

Medium voltage electric motors with increased safety type of protection present a fairly high risk of explosion, also because of the sparking phenomenon that can occur in the stator windings (including partial discharges). These phenomena shall be avoided by the construction of the motor and especially of the insulation system of the stator winding. Motors with type of protection increased safety "eb" can work in zone 1, and when the motor is stopped, inside the housing explosive mixture may enter. When starting the motor, overvoltage can be generated, much higher than the rated voltage, and if windings are not properly insulated, sparking may occur. For this reason it is important that the motors are tested in accordance with the requirements in force.

To prevent the risk of explosions due to rotor sparking during starting the motor can be purge with clean air or with a gas which is not explosive as it is done on the pressurised electric motors.

In this paper was revealed the importance of the tests carried out on electric motors used in potentially explosive atmosphere and the aspects that should be considered when starting the motors. Also after the studies made in the laboratories, to increase the quality of the tests, it became necessary to acquire a pulse generator, an adjustable voltage source and a precise data acquisition system for temperature measurement with $400 \mathrm{~V}$ isolated channels and accessories. The modernization of the test stands will lead to the increase of the quality of the tests, finally resulting in an increased level of safety and health at work for the workers who operates in the industries with danger of explosive atmosphere.

In order to protect people who work in explosive environments, it is important that equipment operating in such areas to comply with the requirements in force, and be properly maintained by personnel who know the principles of explosion protection.

\section{References}

1. Directive 2014/34/EU, (2014).

2. Standard SR EN 60079-0, (2013).

3. Standard SR EN 60079-7, (2016).

4. Partial discharge test to evaluate windings of low-voltage electric motors with regard to frequency converter capability as well as general insulation strength, Partial discharge brochure.Available on 
https://library.e.abb.com/public/d35ed76b345b4f368192407106435eed/ABB\%20whitepaper_Pa rtial_discharge.pdf

5. D. Pasculescu, L. Pana, V. M. Pasculescu, F. Deliu, Mining of Mineral Deposits, 13 (2), 1-16, (2019)

6. V. M. Pasculescu, N. I. Vlasin, E. Ghicioi, G. D. Florea, M.C. Suvar, Environ Eng Manag J, 18 (4), 889-900, (2019)

7. E. Ghicioi, G. Găman, N. Vlasin, V. M. Păsculescu, D. Gabor, Environ Eng Manag J, 16 (6), 1323-1330, (2017).

8. M. Magyari, S. Burian, L. Moldovan, D. Fotău, M. Rad, C. Colda, Proceedings of the 8th International Symposium on Occupational Health and Safety - SESAM 2017 1, 359-369, (2017).

9. http://www.hse.gov.uk/offshore/infosheets/is3-2010.htm

10. V. M. Pasculescu, S. M. Radu, E. Ghicioi, D. Pasculescu, T. Niculescu, Proceedings of the 14th International Multidisciplinary Scientific GeoConference SGEM 2014, 1 (2), 43-50, (2014)

11. F. G. Popescu, D. Pasculescu, M. D. Marcu, V. M. Pasculescu, Mining of Mineral Deposits, 14 (4), 40-46, (2020) 